\title{
A Review of the Development and Application of Mechatronics
}

\author{
Li Shu-lin ${ }^{1, ~ a *}$, Ju Hua ${ }^{2, b}$ \\ ${ }^{1}$ Engineering Training Center, University of Science and Technology Liaoning, Anshan, 114051, \\ China \\ ${ }^{2}$ School of Applied Sciences, University of Science and Technology Liaoning, Anshan, 114051, \\ China \\ a642468130@qq.com, b1357280818@qq.com
}

Keywords: mechatronics, review, present situation, developing trend

Abstract. Mechatronics is a kind of composite technology, combining the mechanical technology , microelectronics technology and information technology. The mechanical and electrical integration technology is the inevitable trend of the development of machinery industry, and the development of mechatronics technology will be more and more wide. With the development of science and technology, mechatronics products are almost all over the field of manufacturing industry, and the integration of electrical and mechanical technology will be developed in the direction of green, intelligent, networking, miniaturization and modularization. This paper briefly introduces the basic outline and development background of mechatronics technology, summarizes the current situation of mechatronics technology at home and abroad, discusses the new contents of the mechanical and electrical integration of the traditional mechanical engineering, and analyzes several common mechanical and electrical integration products in recent years.

\section{Introduction}

With the rapid development of science and technology, mechatronics technology has become an important part of Industrial Science and technology. The mechatronics technology is based on the system's point of view, using the technology of mechanical technology, microelectronics, automatic control, computer technology, information technology, sensing technology, power electronic technology, interface technology, information technology and software programming technology, to allocate the functional units rationally, realize specific functions in the multifunction, high quality, high reliability and low energy consumption, and make the whole system optimization.

The IEEE/ASME gave a more comprehensive definition in 1996: " mechatronics " is defined as "collaborative integration of mechanical engineering and electronic and intelligent computer control in the design and manufacturing of industrial products and processes."This definition contains 11 aspects , " forming and design; system integration; actuators and sensors; intelligent control; robot; manufacturing; motion control; vibration and noise control; micro device and optoelectronic systems; automotive systems; other applications". At present, the Japanese definition is widely used in the world, "Mechatronics is a general term for the introduction of micro electronics technology in the mechanical function, power function, information function and control function, and the organic combination of the mechanical device and the electronic device"[1].

\section{Development of Mechatronics in foreign countries}

The development of Mechatronics can be divided into three stages: the first stage (also known as the primary stage) is 1960 s, this period people do not consciously use electronic technology and make it more widely recognized; the second stage, the mechanical and electrical integration technology and product has been greatly developed; the third stage, countries have begun to pay great attention to and support the integration of technology and products. 
In the late 1990s, the mechatronics technology entered into the period of development. Optical, communications, micro machining technology entered the integration of the mechanical and electrical integration, emergencing a new branch of optical and electrical integration and micro electromechanical integration. At the same time, the modeling design, analysis and integration method, and the development trend of mechatronics system are studied. Artificial intelligence technology, neural network technology and optical fiber technology have opened up a broad development space for the mechatronics technology[2].

Mechatronics products developed rapidly mainly in the following 4 aspects :

(1)Laser technology entered into the field of mechanical and electrical integration. The combination of laser technology and mechanical and electronic technology not only greatly expanded the application fields of mechatronics, but also made some major changes in the industry. It is the best combination of information industry and manufacturing industry.

(2) Micro machining technology and equipment development. The rapid development of micro electronics technology and its industry, driven by the rise of a large number of high and new technology, micro machining technology and equipment not only supports the development of the electronics industry, and the birth and development of micro machinery also played a decisive role.

(3) Mechatronics transitted from single machine to the whole manufacturing industry. Computer integrated manufacturing system (CIMS) is the current world manufacturing industry development general trend, it breaks the boundaries between departments of the original to make for the backbone to control the "logistics" and "flow", from the management decision, product development, production preparation, production experiment to the production and management of organic combination. The realization of CIMS is the optimal synthesis of global dynamics.

(4) Mechatronics products are almost all in all manufacturing areas. In the industrial developed countries, CNC machine tools accounted for the total number of $30 \% \sim 40 \%$. The industrial robot is developing in the direction of intelligent and intelligent systems, and the number of industrial robots will grow at the rate of $25 \% \sim 30 \%$ in the next ten years. Intelligent robots will gradually enter the office, management, entertainment, family and other fields.

\section{Development of Mechatronics in China}

From the beginning of 1980s, we have carried on the research and application of mechatronics. The State Council has set up the leading group of mechatronics and has been listed as "863 Plan" ". In the development of the "Nine Five" plan and the 2010 development outline took full consideration of the international development trend of mechatronics technology and the impact of this may bring. Many colleges, research institutions and some large and medium enterprises has done a lot of work on the development and application of this technology. Although there is still a certain gap between the domestic and the advanced countries such as Japan, Europe and the United States, China has stepped up its research on mechatronics technology.Through making it a nationally important research area and giving priority to support, China has made some achievements[3].

\section{(1)Industrial robot}

Our country included the robot research development in the national science and technology plan in 1986, and has now mastered the robot manipulator design manufacturing technology, control system and software programming technology, kinematics and trajectory planning techniques, and producted some critical components of the robot, and entered the practical stage. Robots are invented for multiple applications, such as welding, spot welding, painting, assembly, handling, injection molding, stamping , walking forward and backward, climbing, and underwater operation.

\section{(2) Numerical control technology}

China's numerical control technology started in 1958, and in the end of the "Nine Five", the domestic CNC machine tool's domestic market share reached 50\%, with the configuration of domestic CNC system (Universal) reaching 10\%. Throughout the development of the numerical control technology in the last 50 years, especially after five four year plan of research, the whole point of view 
has achieved good results. At present, the annual production capacity is more than 3000 sets of CNC system, and 5000 sets of feed and spindle device .Over the past decade, general NC machine tool machining accuracy has increased from $10 \mu \mathrm{m}$ to $5 \mu \mathrm{m}$, precision machining center increased from 3 to $5 \mu \mathrm{m}$ up to $1-1.5 \mu \mathrm{m}$ and ultraprecision machining accuracy has begun to enter the nanoscale $(0.01$ $\mu \mathrm{m})$.

\section{(3) Mechatronics in automobile}

The mechatronics technology of the automobile is based on the microcomputer as the center of the vehicle to improve the performance of the car, increase the function of the automobile, reduce fuel consumption, reduce the exhaust pollution, improve the safety, reliability, operation convenience and comfort. The key is the engine ignition, fuel injection, air fuel ratio and exhaust gas recirculation, to reduce pollution, save energy, realize the automatic transformation and exhaust gas purification control, and also to make the best of its driving state, the car's anti-slip braking, anti-impact, to improve the safety of the car, automatic air conditioning, automatic high speed steering control, to improve its comfort. In recent decades, the international automobile companies have increased their research on the mechanical and electrical integration, so that the development of a qualitative leap[4].

\section{Developing trend of mechatronics}

Mechatronics technology is the integration of many subjects such as mechanical, electronic, optical, control, computer, information and so on. Its development and progress depends on and promotes the development and progress of related technologies. In twenty-first Century, the most important development directions of mechatronics technology are: intelligent, digital, networking, micro and green. The following is a brief discussion:

\section{(1) Intelligence}

Intelligence is an important developing direction in the development of mechatronics technology in twenty-first Century. Artificial intelligence in the study of the mechanical and electrical integration of the builders of the growing importance of the robot and the intelligent machine tool is an important application. The "intelligence" is a description of the machine behavior , based on the control theory, absorbing the new ideas, new methods, such as artificial intelligence, operational research, computer science, fuzzy mathematics, psychology, physiology and chaotic dynamics. Indeed, making mechatronics products equally intelligent with human is not possible, nor is it necessary. However, high performance and high speed microprocessors making the mechatronics product endowed with low intelligence or intelligent, is entirely possible and necessary.

\section{(2) Miniaturization}

Micro electro mechanical integration system is the product of mechatronics technology in nano scale. It is a new development direction of mechatronics. Micro electromechanical integration products are the mechanical and electrical integration products, which is not more than a cubic centimeter in size. This kind of product has the characteristics of small size, small energy consumption and flexible movement. In the biological medical, military, information and other aspects of incomparable superiority, it is one of the key technologies in recent and future development.

\section{(3) Green}

Environment, resources, population is the three major themes of human society. In particular, the environmental problems, the degree of deterioration, is a serious threat to the survival and development of human society, and the problem of resources is not only related to the limited resources of the human world, but also the main source of environmental problems. So in recent years, a new concept has been proposed: the most effective use of resources and the highest utilization of waste, is the current world environment problem of the road[5].

\section{(4) Systematization}

One of the features of the system is to use the structure of the system and the structure of the system. System can be flexible set, for any reduction and combination, at the same time to achieve multi - axis series control functions of the NC system. Performance characteristics of the two is greatly 
enhanced, that is, the network trend[6]. Because of the rise and development of network technology, the network based remote control and monitoring technology is in the ascendant, and remote control terminal equipment itself is the mechanical and electrical integration products. Therefore, the mechanical and electrical integration products will undoubtedly be in the direction of network development.

\section{Summary}

In summary, the mechatronics is the crystallization of many scientific and technological development, and also is the inevitable requirement for the development of social productive forces to a certain stage. It is pointed out that the mechatronics technology is a strategic change, the traditional mechanical design method and design concept is undergoing a revolutionary change, the new method to create, to find. Twenty-first Century, the mechanical and electrical integration technology will play a leading role in the mechanical industry. Mechanical and electrical integration technology is the penetration of all machinery products in the common technology, almost no industry restrictions. The mechatronics technology is the inevitable trend of the development of the machinery industry by the organic combination of mechanical technology and micro electronics technology.

\section{References}

[1] J.M Zhang. Design of mechatronics system . Beijing Institute of Technology Press, Beijing,1996.

[2] J.Y Liang, Y.X Li, S.Z Lin. The development and application of mechatronics.Technical information, 2007(25) :53-54.

[3] Histand M B, Alciatore D G. Introduction to mechatronics and measurement systems. McGraw-Hill series in mechanical engineering, 1999:3-25.

[4] Preumont A. Mechatronics : dynamics of electromechanical and piezoelectric systems[J]. Springer Netherlands, 2010.

[5] Wei W. Mechatronics and It's Applications[J]. Equipment Manufacturing Technology, 2009.

[6] IEEE. IEEE Transactions on Mechatronics /[J]. IEEE Transactions on Antennas \& Propagation, 2013, 45(10):2196-2206. 